\title{
ORGANIZAÇÕES VOLUNTÁRIAS:
}

informação para a conquista da cidadania ${ }^{1}$

VOLUNTARY ORGANIZATIONS: information for citizenship

\author{
Maria Lorena Selbach Figueiró - Email lfigueiro@mp.sc.gov.br \\ Francisco E. P. Sousa \\ Nivaldo Gomes Rebelo \\ Acadêmicos do Curso de Biblioteconomia da UFSC
}

\section{Resumo}

Pesquisa que procura refletir sobre o papel da informação nos movimentos sociais representados pelas organizações voluntárias (organizações não-governamentais ONGs e organizações de mútua-ajuda) de Florianópolis-SC. Objetiva verificar até que ponto tais entidades, através da informação, colaboram no processo de inclusão social do seu público alvo, isto é, favorecem via processos informacionais, o exercício da cidadania.

Palavras-chave: organizações não-governamentais, movimentos sociais, organizações de mútua-ajuda, cidadania, informação.

\section{INTRODUÇÃO}

Neste começo de século, tudo se transforma. O mundo parece estar em permanente evolução e o ser humano em busca contínua de reconhecimento de seus direitos como cidadão.

O que seria cidadania?

A palavra cidadania é derivada de cidadão, que vem do latim civitas, assim como polis que vem do grego. Ambas significam cidade. Na Roma antiga a cidade era a comunidade organizada politicamente e era considerado cidadão aquele que estava integrado na vida social e política da cidade.

A expressão cidadania vem sofrendo alterações ao longo do tempo, resultantes das pressões exercidas pelos excluídos de seus direitos ou forçada pelos modelos

1 Relato de pesquisa apresentado no Seminário Semestral do Curso e Biblioteconomia da UFSC, $2^{\mathrm{a}}$ etapa, realizado em abril de 2001. Pesquisa realizada na Disciplina CIN5440 Metodologia da Pesquisa, orientada pela Prof ${ }^{a}$. Edna Lúcia da Silva. 
econômicos, políticos e sociais dentro de um processo histórico de tentativa de resgate da dignidade do ser humano.

Na visão de Covre (1993), cidadania é o próprio direito à vida no seu sentido pleno. Trata-se de um direito que precisa ser construído coletivamente, não só em termos de atendimento às necessidades básicas, mas de acesso a todos os níveis de existência, incluindo o mais abrangente, o papel do homem no universo.

Pode-se, também, tentar responder tal questão procurando entender como se constrói a cidadania ou como se processa a cidadania no âmbito da sociedade.

Marshall (1967) aponta três direitos como constitutivos dos direitos da cidadania. Os direitos civis, os direitos políticos e os direitos sociais. Direitos civis dizem respeito aos direitos do indivíduo na sociedade e se referem à liberdade individual. Direitos políticos são assegurados pelos direitos civis e estão relacionados ao exercício do poder, através do voto ou da representação política. Os direitos sociais devem garantir o bem-estar social e, conseqüentemente, a dignidade humana.

Scherer-Warren (1995, p. 4 ) acredita que a cidadania é algo a ser conquistado. Esta conquista se realiza em vários níveis, assim por ela destacados:

1. "Conquista de novos direitos e de incorporação dos chamados direitos de terceira geração (de gênero, ambientais, étnicos etc.);

2. Reconhecimento do direito de ter direitos, principalmente entre determinados setores da sociedade, como entre os denominados 'excluídos sociais';

3. Cumprimento dos direitos, das leis estabelecidas e não observadas. No Brasil, o cidadão em geral não tem o hábito de se defender e ou fazer respeitar seus direitos, é um quase-cidadão, como nos casos de consumidores lesados, de descaso no atendimento à saúde, na falta de vagas nas escolas, nas filas de aposentados etc.”.

A formação da cidadania, para Benevides (2000), pode ser feita no sentido formal e informal. No sentido mais formal, se processa através do sistema regular de ensino, escola, ensino fundamental, ensino universitário, etc. No sentido informal, através de 
participação em movimentos sociais, de associações, das ONGs, de partidos políticos em seus programas de formação etc.

Da mesma forma, Rocha (2000) considera que a construção da cidadania realiza-se através do conhecimento do mundo, adquirido, formal e informalmente, a partir das experiências e do convívio em sociedade, pelas trocas lingüísticas. Para a autora, a construção da cidadania é fruto de um processo sistemático de formação intelectual e moral do indivíduo.

Araújo (1999) pontua que a construção da cidadania ou de práticas da cidadania passa pela questão do acesso e uso da informação isto porque, tanto a conquista de direitos políticos, civis e sociais, quanto a implementação dos deveres do cidadão dependem do livre fluxo de informação sobre tais direitos e deveres. $\mathrm{O}$ exercício da cidadania, neste prisma, depende da ampla disseminação e circulação da informação e de um processo de discussão e crítica sobre as diferentes questões que envolvem a vida do cidadão.

Os direitos de cidadania são assegurados mundialmente pela Declaração Universal dos Direitos Humanos, aprovada pela Organização das Nações Unidas em 1948. Os Direitos Humanos universais incluem os direitos individuais fundamentais. No Brasil, os direitos de cidadania são assegurados pela Constituição Federal. Teoricamente, tais direitos já estão estabelecidos pela legislação e deveriam alcançar todos os indivíduos, sem restrições. Na prática os direitos de cidadania não são observados na sua totalidade. Existe, no Brasil, uma grande maioria da população excluída e sem acesso a bens materiais e intelectuais que possibilitem o exercício pleno da sua condição de cidadãos.

O processo de ampliação dos direitos de cidadania relaciona-se com os processos de democratização da sociedade que se efetiva via disseminação livre de informação. Apesar dos direitos de cidadania serem direitos assegurados constata-se que nem sempre são usufruídos em sua plenitude por todos os cidadãos. Buscando minimizar essa questão a humanidade tem se mobilizado. Nos últimos tempos, ocorreram alterações significativas na sociedade civil, neste sentido. Uma delas é o aparecimento dos movimentos sociais voluntários. Estes movimentos representam uma forma de luta 
alternativa pelos direitos do cidadão e buscam substituir a representatividade falida dos partidos políticos. Tais movimentos modernamente fazem parte do terceiro setor da sociedade civil ao lado do Estado (sistema burocrático-administrativo e governamental) e do Mercado (sistema produtivo). O terceiro setor, portanto, caracteriza-se como não governamental e sem fins lucrativos.

A presente pesquisa tem como foco de abordagem os movimentos sociais representados pelas Organizações Voluntárias de Florianópolis. Pretende levantar algumas organizações em Florianópolis e através da forma de atuação dessas organizações verificar o uso da informação para o exercício da cidadania.

\section{OS MOVIMENTOS SOCIAIS}

Florianópolis destaca-se como um pólo turístico, por ter 42 praias e uma paisagem diversificada. Por outro lado, um dos problemas centrais da cidade é o crescente processo de favelização, fruto do êxodo rural e do empobrecimento da população. Os migrantes, quando aqui chegam, instalam-se em favelas, caem no subemprego e na marginalidade.

Na busca da transformação social, surgem os movimentos sociais que tentam melhorar a vida destes cidadãos, procurando prestar assistência aos grupos de excluídos e de marginalizados da sociedade. Os movimentos sociais representam, então, "formas de ação coletiva que ao longo do tempo vêm reagindo, como expressão política, aos contextos de dominação e exploração da população colocada à parte do processo de desenvolvimento econômico, do acesso aos bens simbólicos e materiais produzidos pelo esforço da sociedade como um todo" (Marteleto, 2001, p.1).

Os movimentos sociais, neste sentido, ganham expressão através das organizações voluntárias: organizações não-governamentais (ONGs) e organizações de mútua-ajuda. Organizações voluntárias são aquelas que funcionam com base no "associativismo voluntário que comporta um ideal de transformação da sociedade, de aspectos da 
comunidade ou das relações sociais". Referem-se ao "associativismo a serviço da comunidade, do interesse público, da resolução de questões e problemas prementes na sociedade civil, tais como as relativas às carências sociais, à degradação do meio ambiente, à saúde, a bens e equipamentos coletivos urbanos, à participação na gestão de bens e serviços públicos, às ações para cidadania e às questões de natureza semelhante" (Scherer-Warren, 1996, p.13).

As ONGs, segundo Scherer-Warren (1999), são organizações formais, privadas que tem fins públicos e não tem fins lucrativos. São organizações auto-governadas e com participação voluntária de grande parcela de seus membros. Atuam através de mediações educacionais, políticas ou prestam assessoria técnica ou serviços; podem ainda oferecer material de apoio, de assessoria e de promoção ao desenvolvimento sócio-econômico, à construção da cidadania ou ao bem-estar social.

Os grupos de mútua-ajuda, segundo Scherer-Warren (1999), caracterizam-se como agrupamentos coletivos formalizados, que visam prestar apoio e/ou serviços de ajuda recíproca. Objetivam promover melhorias e transformações positivas no bem estar e na saúde psíquica de seus membros.

\section{OBJETIVOS}

\subsection{Objetivo geral}

A proposta deste trabalho é caracterizar a atuação de algumas organizações voluntárias, inseridas no contexto social da cidade de Florianópolis, capital do Estado de Santa Catarina.

\subsection{Objetivos específicos}

1. Identificar as organizações voluntárias;

2. Caracterizar a atuação das organizações voluntárias;

3. Verificar o fluxo de informação das organizações para a população alvo;

4. Analisar os instrumentos de disseminação de informação usados pelas organizações;

5. Levantar as dificuldades das organizações voluntárias nas questões de informação. 


\section{METODOLOGIA}

Tendo em vista o seu objetivo, o universo desta pesquisa constituiu-se das organizações voluntárias de Florianópolis que trabalham com a informação, isto é, as que têm como proposta levar informação adequada, pertinente e contextualizada ao meio sócio-cultural das suas populações-alvo.

A amostra do estudo foi constituída por organizações voluntárias pertencentes às duas classificações: as ONGs e os grupos de mútua-ajuda, cujo compromisso tivesse relação direta com a disseminação da informação. Desta forma, foram selecionadas 5 organizações não-governamentais e 3 organizações dos grupos de mútua-ajuda.

\begin{tabular}{|c|c|c|}
\hline \multicolumn{3}{|c|}{ ONGs - ORGANIZAÇÕES NÃO-GOVERNAMENTAIS } \\
\hline \multicolumn{3}{|c|}{ Nome: CECCA - CENTRO DE ESTUDOS CULTURA E CIDADANIA } \\
\hline Endereço: Rua Felipe Schmidt, 390 - s. 206 & \multicolumn{2}{|c|}{ Bairro: Centro } \\
\hline Cidade: Florianópolis & UF: SC & CEP: $88010-001$ \\
\hline Fone: (48) 224-0576 & \multicolumn{2}{|c|}{ Fax: (48) 224-0576 } \\
\hline \multicolumn{3}{|c|}{ Nome: PROMENOR/ IDES - Irmandade do Divino Espírito Santo } \\
\hline Endereço: Av. Hercílio Luz, 1249-A & \multicolumn{2}{|c|}{ Bairro: Centro } \\
\hline Cidade: Florianópolis & UF: SC & CEP: 88020-001 \\
\hline Fone: (48) 222-6158 / 224-5008 & \multicolumn{2}{|c|}{ Fax: (48) 222-6158 / 224-5008 } \\
\hline \multicolumn{3}{|c|}{ Nome: FUNDAÇÃO FÉ E ALEGRIA DO BRASIL } \\
\hline Endereço: Largo São Sebastião, 88 & \multicolumn{2}{|c|}{ Bairro: Centro } \\
\hline Cidade: Florianópolis & UF: SC & CEP: $88015-530$ \\
\hline Fone: (48) 222-2467 & \multicolumn{2}{|c|}{ Fax: (48) 222-2467 } \\
\hline \multicolumn{3}{|c|}{ Nome: GAPA - GRUPO DE APOIO À PREVENÇÃO À AIDS } \\
\hline Endereço: Rua Felipe Schmidt, 882 & \multicolumn{2}{|c|}{ Bairro: Centro } \\
\hline Cidade: Florianópolis & UF: SC & CEP: 88010-002 \\
\hline Fone: (48) 225-0548 & \multicolumn{2}{|c|}{ Fax: (48) 225-0548 } \\
\hline \multicolumn{3}{|c|}{ Nome: GAPA - LAR RECANTO DO CARINHO } \\
\hline Endereço: Rua Rui Barbosa, s/n ${ }^{\circ}$ & \multicolumn{2}{|c|}{ Bairro: Agronômica } \\
\hline Cidade: Florianópolis & UF: SC & CEP: $88025-030$ \\
\hline Fone: (48) 228-0024 & \multicolumn{2}{|c|}{ Fax: (48) 228-0024 } \\
\hline
\end{tabular}




\begin{tabular}{|c|c|c|}
\hline Endereço: Rua Rui Barbosa, s/n ${ }^{\circ}$ & \multicolumn{2}{|c|}{ Bairro: Agronômica } \\
\hline Cidade: Florianópolis & UF: SC & CEP: $88025-030$ \\
\hline Fone: (48) 228-3232 & \multicolumn{2}{|c|}{ Fax: (48) 228-3232 } \\
\hline \multicolumn{3}{|c|}{ Nome: CVV - CENTRO DE VALORIZAÇÃO DA VIDA } \\
\hline Endereço: Rua Victor Konder, 321 & \multicolumn{2}{|c|}{ Bairro: Centro } \\
\hline Cidade: Florianópolis & UF: SC & CEP: $88015-400$ \\
\hline Fone: (48) 222-4111 & \multicolumn{2}{|c|}{ Fax: (48) 222-4111 } \\
\hline \multicolumn{3}{|c|}{ Nome: REDE FEMININA DE COMBATE AO CÂNCER } \\
\hline Endereço: Rua General Bittencourt & \multicolumn{2}{|c|}{ Bairro: Centro } \\
\hline Cidade: Florianópolis & UF: SC & CEP: $88020-100$ \\
\hline Fone: (48) 223-7722 & \multicolumn{2}{|c|}{ Fax: (48) 324-2259 } \\
\hline
\end{tabular}

O instrumento para coleta de dados utilizado foi um formulário construído para a obter informações das organizações referentes às seguintes variáveis de análise: site, endereço eletrônico, ano da fundação, missão/objetivo, tipo de entidade, âmbito de atuação, forma de atuação, número de funcionários e/ou prestadores de serviços, número de estagiários, número de voluntários e/ou cooperantes. número de profissionais da área da informação, beneficiários principais, divulgação do movimento, filtragem da informação para ter condições de ser assimilada pela população-alvo, tratamento dado à documentação gerada, projetos ilustrativos e publicações da organização.

A metodologia adotada foi baseada em estudo similar desenvolvido por Bréglia \& Gusmão (1986).

\section{RESULTADOS}

Na modernidade, as organizações não-governamentais e os grupos de mútua-ajuda já fazem parte das ações coletivas da sociedade civil. Tais ações estão voltadas para a construção de um mundo socialmente mais justo, mais solidário e mais democrático.

A pesquisa caracterizou nove organizações voltadas para as populações carentes e desassistidas, entre as ONGs e os grupos de mútua-ajuda.

\subsection{Caracterização das organizações}




\section{ONGs - ORGANIZAÇÕES NÃO-GOVERNAMENTAIS}

\section{Nome: CECCA - CENTRO DE ESTUDOS CULTURA E CIDADANIA}

Site: http:// www.ceca.org.br

Endereço Eletrônico: ceca@mbox1.ufsc.br

Ano da fundação: 1990

Missão/objetivo: Democratizar a informação, contribuir para uma cultura crítica e para a ação direta dos cidadãos, desenvolvendo assessoria e pesquisa com os movimentos sociais nas áreas de Ecologia, Cidadania, Problemas Urbanos, Educação Popular e Relações de Gênero.

Âmbito de atuação: Municipal

Forma de atuação: Atua no sentido de articular e interligar os tradicionais movimentos sociais: sindicatos, moradores, com os novos movimentos: ecológicos e feministas, buscando o fortalecimento da sociedade civil. Desenvolve, através de seus vários grupos, um trabalho de educação popular, assessoria a movimentos sociais, cursos e seminários. O CECCA/SC tem mantido uma posição rigorosamente autônoma e apartidária, sendo um espaço de encontro plural de cidadãos, que desejam intervir ativamente na sua cidade. Suas causas estão relacionadas com a cidadania, a ecologia e as relações de gênero, o apoio jurídico, a metodologia e a educação popular.

O CECCA desenvolve vários projetos e atividades:

1. acompanhou ativamente os trabalhos preparatórios do Fórum Global, participando diretamente da organização do ECOFÓRUM estadual, tendo sido um dos principais articuladores do Fórum das Entidades Civis sobre Meio Ambiente e Desenvolvimento da Região da Grande Florianópolis.

2. participou da coordenação do Fórum Estadual de Organizações Não-governamentais e do Fórum Sul de ONGs. O CECCA é membro da Federação de Entidades Ecologistas Catarinenses, da Rede Mata Atlântica, do Fórum Agenda 21 Local e foi um dos representantes das entidades ecologistas no Conselho Municipal de Meio Ambiente.

3. participou da discussão, o longo dos últimos anos, do Orçamento Participativo do Município e do Plano Diretor de Florianópolis, fóruns públicos em que foram 
discutidos alguns dos temas centrais com que se vem debatendo nossa cidade, no seu processo caótico de crescimento.

4. participou da co-organização do Encontro Catarinense Preparatório da Conferência da ONU Habitat II (1995).

5. aprovou o projeto "Levantamento e Divulgação de Informações Sobre a Realidade Sócio Ambiental da Ilha de Santa Catarina" junto ao Fundo Nacional do Meio Ambiente do Ministério do Meio Ambiente (1995). Este projeto desenvolvido ao longo de 1995, visou entre outros objetivos, ampliar o conhecimento dos cidadãos sobre a realidade local, possibilitando assim uma maior consciência dos problemas sócio-ambientais, subsidiar políticas locais alternativas, que contribuam para inverter o atual quadro de crescimento desordenado e de degradação do meio ambiente e da qualidade de vida na Ilha de Santa Catarina. Permitiu realizar um amplo levantamento bibliográfico e documental sobre a realidade local, uma pesquisa em seis diferentes comunidades da Ilha, sendo criada simultaneamente uma base de dados, que permite apoiar o trabalho de educação ambiental comunitária. Resultante deste projeto foi publicado o livro "Uma cidade numa Ilha, Relatório sobre os Problemas sócio-ambientais da Ilha de Santa Catarina" e montada a exposição Encruzilhadas da Ilha, que vem percorrendo escolas do município. O CECCA recebeu por este trabalho o prêmio Burle Marx no III Encontro LatinoAmericano de Educadores Ambientais realizado em Outubro de 1995 no Rio de Janeiro,

6. aprovou o projeto "Criciúma - Área Crítica Para Questões de Meio Ambiente : Um levantamento de Projetos e Propostas" financiado pela FEEC (Federação de Entidades Ecologistas Catarinenses) através do Fundo Solmad (Fundo de Solidariedade Para o Meio Ambiente e Desenvolvimento) e CEMA-I ( Centro de Enlace Para o Meio Ambiente Internacional) (1991). Nesse mesmo ano, convocou o Fórum Cidade de Florianópolis que reuniu entidades da sociedade civil e pesquisadores da universidade para discutir os problemas da região e pensar um projeto para a cidade.

O CECCA está dando continuidade às suas atividades de educação ambiental, de acompanhamento das políticas públicas locais, principalmente no que se refere ao planejamento urbano. Tem mantido, também, as seguintes atividades: 
1. Pesquisa e divulgação de informações sobre a realidade sócio-ambiental da Ilha de Santa Catarina, com o apoio do Fundo Nacional do Meio Ambiente.

2. Publicação a segunda. edição do livro "Uma Cidade numa Ilha - Relatório sobre os problemas sócio-ambientais da Ilha de Santa Catarina".

3. Edição de livro sobre as Unidades de Conservação da Ilha de Santa Catarina, com o apoio do Fundo Nacional do Meio Ambiente/Ministério do Meio Ambiente e do BESC - Banco do Estado de Santa Catarina.

4. Projeto Informática e Cidadania - Capacitação de jovens carentes no uso da informática. Projeto conjunto com a Escola Autonomia.

5. Projeto de gestão participativa da Estação Ecológica de Carijós, em convênio (de colaboração) com o IBAMA.

6. Indicadores de qualidade de vida e educação ambiental na Ilha de Santa Catarina, (projeto) apoiado pelo Fundo Nacional do Meio Ambiente.

\section{Profissionais envolvidos:}

1. Número de funcionários e/ou prestadores de serviços: 0

2. Número de estagiários: Atuam somente durante os projetos em andamento

3. Voluntários e/ou cooperantes: 20

4. Profissionais da área da informação: 0

Filtragem da informação para a população-alvo: A população-alvo recebe a informação em linguagem adequada através de boletins, folhetos e exposições.

Tratamento dado à documentação gerada: A documentação é organizada e arquivada e está disponibilizada na Internet.

Nome: PROMENOR/ IDES - Irmandade do Divino Espírito Santo

Site: http://www.prodau.com.br/irmandade

Endereço Eletrônico: ides@netco.com.br

Ano da fundação: 1971

Missão/objetivo: Sua missão é atuar na assistência e na formação de crianças e adolescentes em situação de vulnerabilidade, visando promover a cidadania e o desenvolvimento social.

Âmbito de atuação: Municipal 
Forma de atuação: Atende em torno de 1100 crianças e adolescentes e famílias em situação de exclusão, da Grande Florianópolis. No contexto das atuais transformações, a PROMENOR/ IDES busca viabilizar um processo de formação contínua que permita as crianças e adolescentes adquirir habilidades que lhes possibilitem competir no mercado de trabalho, buscando desenvolver espírito empreendedor, criatividade, iniciativa, motivação e capacidade crítica para o exercício de sua cidadania.

\section{PROGRAMAS PROMENOR/ IDES:}

1. Abrigo Lar São Vicente de Paulo

2. Jardim de Infância e Pré-Escolar Girassol - JIG

3. Programa Espaço Alternativo do Saber - PEAS

4. Centro de Aprendizagem Profissional - CEAP

5. Programa Jovem Trabalhador - PJT

6. Oficina Educativa

\section{Profissionais envolvidos:}

1. Número de funcionários e/ou prestadores de serviços: 100

2. Número de estagiários: 40

3. Voluntários e/ou cooperantes: 200

4. Profissionais da área da informação: 0

Filtragem da informação para a população-alvo: O material informativo, em forma de folheto e publicações similares, é elaborado em linguagem simples e clara para atingir os objetivos propostos junto à população-alvo.

Tratamento dado à documentação gerada: Toda documentação é arquivada.

Nome: FUNDAÇÃO FÉ E ALEGRIA DO BRASIL - Sub-Regional Santa Catarina Site: http://www.fealegria.org.br

Endereço Eletrônico: fealegri@matrix.com.br

Ano da fundação: 1993

Missão/objetivo: Promover uma educação integral, de qualidade, comprometida com os princípios cristãos de igualdade, justiça e solidariedade, capaz de tornar crianças e adolescentes em sujeitos autônomos, visando à transformação social, em parceria com as camadas populares. Procura garantir a cidadania de crianças e adolescentes excluídos dos direitos sociais. 
Âmbito de atuação: Regional / Nacional / Internacional. No âmbito regional atua nas cidades de Florianópolis, São José e Palhoça.

Forma de atuação: Atua nas áreas da Educação, Defesa de Direitos, Desenvolvimento Comunitário, Formação de Educador e Comunicação. Atua tendo como base o Estatuto da Criança e do Adolescente - Lei 8.069/90, que aponta com "prioridade absoluta às crianças, o respeito a sua condição peculiar de desenvolvimento e como 'sujeitos de direitos', partícipes de seu processo de desenvolvimento".

Desenvolve os seguintes projetos:

1. Sócio-Educativo: desenvolve atividades de educação ambiental, arte, cultura, lazer, esporte, cidadania e apoio pedagógico com crianças e adolescentes das comunidades Chico Mendes e Nossa Senhora da Glória / Florianópolis e Ponte do Imaruim / Palhoça.

2. Sócio-Familiar: presta orientação e apoio às famílias residentes nas comunidades Chico Mendes e Nossa Senhora da Glória, bem como às famílias envolvidas nos outros projetos da Fundação.

3. Educação Social de Rua: desenvolve ações de educação social de rua, com os meninos e meninas de rua de Florianópolis e São José, buscando dar continuidade ao diagnóstico envolvendo os meninos(as) de rua de São José. Procura mapear a situação dos meninos(as) que circulam pelas ruas de Florianópolis, identificando a procedência, a ocupação, a escolaridade, o vínculo familiar e o cotidiano de sobrevivência.

\section{Profissionais envolvidos:}

1. Número de funcionários e/ou prestadores de serviços: 07 funcionários e 02 prestadores de serviços

2. Número de estagiários: 03

3. Voluntários e/ou cooperantes: Não tem.

4. Profissionais da área da informação: Não tem

Filtragem da informação para a população-alvo: A área de atuação é muito abrangente, contudo a organização procura disseminar a informação em folhetos e publicações similares usando uma linguagem acessível ao nível sócio-cultural da população-alvo.

Tratamento dado à documentação gerada: A documentação é arquivada. 


\section{Nome: GAPA - GRUPO DE APOIO À PREVENÇÃO À AIDS}

Site: http://solidariedade.uol.com.br/entidades/gapa

Endereço Eletrônico: gife122@uol.com.br

Ano da fundação: 1987

Missão/objetivo: Resgate da cidadania dos doentes. Luta pela melhoria da qualidade na assistência médico-hospitalar oferecida às pessoas portadoras do HIV e pela garantia de medicamentos, prevenção, e contra o preconceito e discriminação.

Âmbito de atuação: Municipal / Estadual

Forma de atuação: Defende os direitos das pessoas com HIV / AIDS, lutando contra os preconceitos e a discriminação. Contribui para a melhoria da qualidade de vida destes portadores, através do combate às informações distorcidas, tendenciosas e alarmistas. $\mathrm{O}$ desenvolvimento de suas atividades se dá através de:

1. Palestras em escolas, empresas e comunidade.

2. Treinamentos e cursos para multiplicadores de informação sobre AIDS.

3. Distribuição de material informativo e de preservativos.

4. Orientação individual.

5. Encaminhamento a outras entidades e/ou serviços.

6. Serviços de informação e programas específicos.

Os programas mantidos atualmente são:

1. DISQUE-AIDS que é um serviço de informação sobre AIDS por telefone, prestado de forma anônima. Qualquer pessoa que ligar para o número (48)-1510 terá suas dúvidas esclarecidas sem ser obrigado a se identificar, sem pagar taxas extras, somente a tarifa ou impulsos normais da sua conta telefônica.

2. Projeto Consciência que é um programa educativo para informação e orientação sobre doenças sexualmente transmitidas (DST) e sobre a síndrome de insuficiência adquirida (AIDS). O programa é destinado a garotos de programa (michês) e desenvolvido nos locais de prostituição masculina na grande Florianópolis. Atua através distribuição de preservativos e aconselhamento individual conscientizandoos a respeito de formas de prevenção dessas doenças e da necessidade da adoção de práticas sexuais seguras. 
3. Desperta Mulher que é um grupo de auto-ajuda para mulheres portadoras do HIV/AIDS. As reuniões são realizadas uma vez por semana e tem como objetivo a busca de solução para problemas comuns associados a convivência com HIV/AIDS e o resgate da auto-estima através do compartilhamento de experiências pessoais de cada uma.

4. Grupo de Auto-ajuda que é um grupo a dar apoio aos usuários de drogas, portadores ou não do HIV, familiares, amigos ou voluntários que simplesmente desejem saber mais sobre drogas ou AIDS.

\section{Profissionais envolvidos:}

1. Número de funcionários e/ou prestadores de serviços: 03

2. Número de estagiários: 0

3. Voluntários e/ou cooperantes: 20

4. Profissionais da área da informação: 0

Filtragem da informação para população-alvo:. O material informativo (folhetos e publicações similares) é divulgado em linguagem simples e clara para atingir os objetivos propostos e permitir a compreensão da população-alvo.

Tratamento dado à documentação gerada: Há uma grande preocupação com o registro dos documentos relacionados aos portadores do HIV/AIDS. É tudo arquivado e controlado. Quanto aos materiais informativos e legislação não há tratamento algum, simplesmente são deixados em uma estante. Existe bastante informação, mas está totalmente desorganizada.

\section{Nome: GAPA - LAR RECANTO DO CARINHO}

Site: http://solidariedade.uol.com.br/entidades/gapa

Endereço Eletrônico: não tem.

Ano da fundação: 1992

Missão/objetivo: Acolher, em regime de internato, crianças de zero a seis anos, filhos de pais portadores do HIV/AIDS, órfãos ou em situação de abandono.

Âmbito de atuação: Estadual

Forma de atuação: As atividades desenvolvidas no Lar Recanto do Carinho visam a satisfação das necessidades básicas da criança para seu perfeito desenvolvimento 
psicossocial e a garantia de uma melhor qualidade de vida. Atua no acompanhamento pedagógico, médico e psicológico das crianças.

\section{Profissionais envolvidos:}

1. Número de funcionários e/ou prestadores de serviços: 32

2. Número de estagiários: 15

3. Voluntários e/ou cooperantes: 35

4. Profissionais da área da informação: 0

Filtragem da informação para população-alvo: Tratando-se de crianças até 6 anos, não existe forma de divulgação específica para essa faixa etária.

Tratamento dado à documentação gerada: A documentação, relacionada ao registro das crianças portadores do HIV/AIDS, é controlada e arquivada.

\section{GRUPOS DE MÚTUA-AJUDA}

\section{Nome: REDE FEMININA DE COMBATE AO CÂNCER}

Site: Não tem

Endereço Eletrônico: Não tem

Ano da fundação: 1986.

Missão/objetivo: Conscientizar às mulheres da importância da prevenção do câncer de colo de útero e da mama.

Âmbito de atuação: Municipal / Regional

Forma de atuação: Atua na prevenção do câncer de colo de útero e da mama, fazendo atendimento ambulatorial. Conscientiza as mulheres sobre a importância de fazer o auto-exame para detectar e tratar o quanto antes a doença.

Suas atividades são desenvolvidas através de:

1. Campanhas e palestras em centros comunitários, onde transmitem as informações e esclarecem as dúvidas quanto ao câncer.

2. Palestras em escolas e empresas.

3. Distribuição de material informativo esclarecendo a importância da prevenção do câncer de colo de útero e mamas.

4. Orientação individual.

5. Encaminhamento a outras entidades e/ou serviços.

6. Serviços de informação e programas específicos. 


\section{Profissionais envolvidos:}

1. Número de funcionários e/ou prestadores de serviços: 2

2. Número de estagiários: 2

3. Voluntários e/ou cooperantes: 42

4. Profissionais da área da informação: 0

Filtragem da informação para a população-alvo: A população-alvo recebe o material informativo em uma linguagem simples e adequada através de folhetos.

Tratamento dado à documentação gerada: A documentação é organizada e arquivada. O registro é feito em fichas preenchidas manualmente.

\section{Nome: AFLODEF - ASSOCIAÇÃO FLORIANOPOLITANA DE DEF. FÍSICOS}

Endereço Eletrônico: Não tem

Ano da fundação: 1985

Missão/objetivo: Promover a integração do portador de deficiência física à sociedade na luta pela cidadania.

\section{Âmbito de atuação: Municipal}

Forma de atuação: A AFLODEF empreende os esforços dos seus associados na conquista da cidadania, através do cumprimento das leis ou reivindicando os seus direitos enquanto cidadãos. Para tanto são efetuados contatos políticos no plano governamental e privado, na área da saúde, da educação, do lazer, do trabalho, etc. Os trabalhos da entidade centralizam-se praticamente sobre atividades esportivas, como um elo de ligação para a integração dos deficientes físicos. Atua também através de debates, palestras e seminários com a sociedade em geral.

\section{Profissionais envolvidos:}

1. Número de funcionários e/ou prestadores de serviços: 86

2. Número de estagiários: 0

3. Voluntários e/ou cooperantes: 40

4. Profissionais da área da informação: 0

Filtragem da informação para população-alvo: A linguagem usada é simples. Os deficientes físicos, na maioria das vezes, são pessoas independentes e não possuem limitações intelectuais, apesar das limitações físicas. 
Tratamento dado à documentação gerada: A documentação é arquivada e divulgada entre os membros associados.

\section{Nome: CVV - CENTRO DE VALORIZAÇÃO DA VIDA}

Site: http://www.cvv.com.br

Endereço Eletrônico: cvvcomunica@terra.com.br

Ano da fundação: 1992.

Missão/objetivo: Prevenção do suicídio através do apoio emocional às pessoas que sofrem, estão angustiadas ou deprimidas e sem vontade de continuar vivendo.

Ambito de atuação: Municipal/Regional/Nacional

Forma de atuação: Atua dando apoio psicológico à população-alvo através de atendimento por telefone ( 24 horas por dia) e pessoal, por meio de seminários, cursos e palestras

\section{Profissionais envolvidos:}

1. Voluntários e/ou cooperantes: Trabalha somente com voluntários não remunerados. Para ser voluntário do CVV é necessário ter mais de 18 anos de idade.

2. Profissionais da área da informação: não informam porque os voluntários têm a identidade resguardada.

Filtragem da informação para a população-alvo: A população-alvo recebe material informativo em linguagem simples e acessível. Publica folhetos e promove palestras. Realiza, anualmente, atividades especiais e palestras na Semana de Valorização pela Vida

Tratamento dado à documentação gerada: A documentação gerada é registrada e arquivada. Possuem poucos documentos, porque a forma de atendimento é realizada principalmente por telefone .

\subsection{Análise das organizações voluntárias}


As organizações voluntárias foram analisadas em função de características semelhantes e/ou pontos de concordância existentes.

Origem: Quanto ao tempo de início das atividades, as organizações concentram-se na década de 80. No final da década de 70 e início dos anos 80, setores da população brasileira se mobilizaram para mudar as condições de vida de segmentos mais vulneráveis da sociedade devido ao descaso governamental. Nesse período, emergem, em vários pontos do país, organizações que se propõem a dar assistência ao segmento infanto-juvenil das camadas populares.

Objetivos: Os objetivos das organizações pesquisadas orientam-se em direção da conquista e resgate da cidadania. Os grupos de mútua-ajuda analisados têm como objetivo principal atuar para a melhoria da saúde psicológica e física de seus membrosparticipantes, através de programas de prevenção, tratamento, apoio a familiares e recuperação de aidéticos, de pessoas propensas ao suicídio e de prevenção como no caso da Rede Feminina de Combate ao Câncer. Alguns grupos também indicam a conquista da cidadania, definida no plano do direito à saúde e do respeito ao doente, entre seus objetivos fundamentais. As ONGs analisadas voltam-se mais para as questões relativas à educação, assistência e defesa dos direitos das crianças e adolescentes.

Temática: Quanto às formas de atuação das organizações voluntárias, a maioria recai na promoção e defesa de direitos das minorias. Nas ONGs, destaca-se a educação continuada voltada às crianças e adolescentes, como forma de programação de atividades. Além disso, realizam seminários, cursos, palestras, exposições e reuniões de grupo como meios de atingirem suas metas no plano político-educacional. Os grupos de mútua-ajuda também desenvolvem suas atividades através de reuniões de grupos. Além disso, palestras, cursos e seminários ocorrem com alguma freqüência, bem como a prestação de serviços voluntários à população-alvo.

Profissionais envolvidos: Na maioria das organizações, os profissionais atuantes são voluntários/cooperantes. Não foi encontrado, nenhum profissional da informação atuando nestas organizações. 
Tratamento da informação: As informações, quando organizadas, estão distribuídas em pastas por tópicos de interesse de cada organização, ordenadas alfabeticamente e armazenadas em arquivo. As entidades relacionadas à saúde, são as que se preocupam em registrar os documentos para poder avaliar/controlar o trabalho desenvolvido. Com No processo de divulgação, não há uma preocupação evidente com a periodicidade.

Papel da informação: A informação é fundamental nestas organizações. É através da informação processada, filtrada e disseminada, que as pessoas ficam cientes de seus direitos e começam a reivindicá-los. A cidadania pressupõe participação efetiva dos homens na sociedade e se realiza através da conscientização e essa, por sua vez, só se processa via informação.

\section{CONCLUSÃO}

Para que a democracia se consolide, faz-se necessário que existam condições institucionais pelas quais os cidadãos possam intervir na vida política, participando e influindo nas decisões de seus interesses. As organizações voluntárias têm através de suas ações, que envolvem disseminação da informação, favorecido o exercício da cidadania e a conseqüente participação dos cidadãos na sociedade. Assim, fica claro que o acesso à informação dá mais condição ao exercício pleno da cidadania. Targino (1991, p. 155) reforça este ponto de vista quando afirma que a informação "é um bem comum, que pode e deve atuar como fator de integração, democratização, igualdade, cidadania, libertação, dignidade pessoal. Não há exercício da cidadania sem informação”.

Portanto, a informação deve caminhar ao lado do homem na construção da cidadania, pois o acesso a esta é primordial para o indivíduo se tornar um cidadão, uma vez que o direito à informação antecede a prática de direitos humanos.

Cabe ressaltar, que as organizações voluntárias trabalham com novos valores que passam a fazer parte de uma nova cultura política em que a luta pelos direitos do cidadão, a participação e a solidariedade tornam-se indispensáveis para a consolidação 
da democracia. A sociedade civil de Florianópolis, através deste trabalho voluntariado, está despertando para as questões da cidadania. As realizações e atividades das organizações voluntárias apontam as seguintes tendências gerais:

As ONGs têm buscado atuar para o fortalecimento da sociedade civil florianopolitana, através de processos pedagógicos e de organização popular, objetivando a restauração de valores éticos e a ampliação da ação para a cidadania. Esta atuação realiza-se através de voluntários e vem buscando contribuições de profissionais.

Os grupos de mútua-ajuda, voltam-se para o abrandamento das questões que envolvem fatores psicossociais dos indivíduos no seu cotidiano. Atuando através de processo terapêutico e voluntário, buscam contribuir para a saúde psicológica, física e espiritual da população interessada.

O que chama a atenção, como resultado desta pesquisa, é a ausência de profissionais da informação nessas organizações isto porque todas, de uma forma ou outra, trabalham com informação, disseminam informação. Tal fato parece indicar que os bibliotecários e outros profissionais da informação ainda não estão sensibilizados para esta questão do voluntariado e da importância de uma participação mais efetiva na luta por uma sociedade melhor e mais justa para todos.

De uma forma geral, as organizações voluntárias, objeto deste estudo, estão voltadas para resolver problemas relativos às necessidades humanas, com respeito aos direitos de cidadania e ao bem-estar dos indivíduos no seu meio social.

As dificuldades das organizações na questão da informação são relativas a mobilização de recursos humanos especializados, através da participação voluntária.

Fundamental, portanto, é saber que os movimentos sociais se valem da informação para, através de um processo de co-responsabilidade e solidariedade social, construir um espaço social mais justo e digno e onde todos possam se sentir incluídos. 


\section{ABSTRACT}

This paper analyses the role of information in social movements represented by voluntary non-governmental and mutual-help organizations in Florianópolis, Santa Catarina, Brazil. The study searches to identify the grade in which such organizations employ information to support the social inclusion of their associates, contributing (through informational proccesses) for their effective citizenship.

KEYWORDS: non-governmental organizations; social movements; citizenship; information

\section{FONTES BIBLIOGRÁFICAS}

ARAÚJO, Eliany Alvarenga de. Informação, sociedade e cidadania: gestão da informação no contexto de organizações não-governamentais (ONGs) brasileiras. Ciência da Informação, Brasília, v.29, n.2, p.155-167, maio/ago.1999.

BENEVIDES, Maria Victoria. $\mathrm{O}$ que é formação para cidadania.. jan.2000. Entrevistador: Sílvio Caccia Bava. Entrevista concedida à Associação Brasileira de Organização não Governamentais, São Paulo. Disponível em: http:www.abong.org.Br>. Acesso em: 10 out.2000.

BREGLIA, Vera Lúcia Alves; GUSMÃO, Helóisa Rios. A informação como fator de democratização. Revista de Biblioteconomia de Brasília, Brasília, v.14, n.1, p. 9-25, jan./jun.1986.

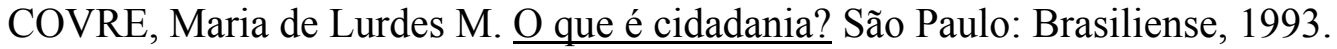

MARSHALL, T. H. Cidadania, classe social e status. Rio de Janeiro: Zahar, 1967.

MARTELETO, Regina Maria. Confronto simbólico, apropriação do conhecimento e produção de informação nas redes de movimentos sociais. DataGramaZero: Revista de Ciência da Informação, Rio de Janeiro, vo.2, n.1, fev. 2001. Disponível em: <http:www.dgzero.org/Atual/F_I_art.htm>. Acesso em: 12 mar. 2001.

ROCHA, Marisa Perrone Campos. A questão cidadania na sociedade da informação. Ciência da Informação, Brasília, v. 29, n. 1, p. 40-45, jan./abr. 2000.

SCHERER-WARREN, Ilse. Cidadania sem fronteiras: ações coletivas na era da globalização. São Paulo: Hucitec, 1999. 95 p.

SCHERER-WARREN, Ilse. Organizações voluntárias de Florianópolis. Florianópolis: Insular, 1996. 93p.

SCHERER-WARREN, Ilse. Redes de movimentos sociais e processos educativos.. Cidadania/Textos, Campinas, n.5, p.2-12, abr.1995.

TARGINO, Maria das Graças. Biblioteconomia, informação e cidadania. Revista Escola de Biblioteconomia da UFMG, Belo Horizonte, v. 20, n. 2, p. 149-160, jul./dez. 1991. 